\section{Acquired toxoplasmosis in children}

Sir,

In their review of acquired toxoplasmosis in children, McNicholl and Flynn (Archives, 1978, 53, 414) suggest the use of sulphadimidine and pyrimethamine for treatment of generalised toxoplasmosis. We report a child with generalised toxoplasmosis who had a dramatic recovery after treatment with co-trimoxazole.

An 11 $\frac{1}{2}$-year-old girl presented to the hospital with an 8-week history of weight loss, fever, malaise, lymphadenopathy, and intermittent muscle pain. There were several cats and dogs in the home. On admission there was pronounced weight loss, generalised lymphadenopathy, erythema nodosum, and muscle tenderness in both quadriceps. On investigation the significant finding was a toxoplasmosis antibody dye test titre of 1:4096. A lymph node biopsy showed histological appearances consistent with toxoplasmosis. As the patient remained unwell 2 weeks after admission she was given a onemonth course of co-trimoxazole ( $400 \mathrm{mg}$ sulphamethoxazole and $80 \mathrm{mg}$ trimethoprim twice daily). A week later her myositis had resolved, the lymphadenopathy decreased, her appetite returned and she was more active and felt better. After one month's treatment her weight had increased by $2.35 \mathrm{~kg}$ and there were no residual signs or symptoms.

A combination of sulphadimidine with pyrimethamine is generally recommended for the treatment of acquired toxoplasmosis, but pyrimethamine can have significant side effects. Co-trimoxazole has been used for 1 to 3 months in the treatment of acquired and congenital toxoplasmosis with encouraging results (Mössner and Auwärter, 1972; Domart et al., 1973; Norrby et al., 1975). As co-trimoxazole is significantly less toxic than pyrimethamine we suggest that it should be the first choice of treatment in toxoplasmosis.

\section{Williams and D. C. L. SAvage Royal Hospital for Sick Children, St Michael's Hill, Bristol BS2 8BJ}

\section{References}

Domart, A., Robineau, M., and Carbon, C. (1973). La toxoplasmose acquisé: une nouvelle chimiothérapie l'association sulfamethoxazole-trimethoprime. Nouvelle Presse Medicale, 2, 321-322.

Mössner, G., and Auwärter, W. (1972). Antibakterielle Wirkung eines neuartigen Chemotherapeutikums. Medizinische Welt, 23, 1306-1309.

Norrby, R., Eilard, T., Syedhem, A., and Lycke, E. (1975). Treatment of toxoplasmosis with trimethoprim-sulphamethoxazole. Scandinavian Journal of Infectious Diseases, 7, 72-75.

Drs McNicholl and Flynn comment:

We are grateful to Drs Williams and Savage for drawing attention to the use of co-trimoxazole in treatment of acquired toxoplasmosis. Although aware of its use in this respect, we were not aware of any extensive trial and preferred to keep to the established combination of a sulphonamide with pyrimethamine.

The treatment of the girl did appear to be very effective, and we would agree that if further trials show similar efficacy, co-trimoxazole should be favoured because it is less toxic than a pyrimethamine/sulphonamide combination.
B. MCNicholl and J. FLYNN Department of Paediatrics, Regional Hospital, Galway, Eiré

\section{Oral rehydration in infantile diarrhoea}

Sir,

Chatterjee et al. (Archives, 1978, 53, 284) conclude that children being rehydrated with an oral glucose electrolyte solution containing $90 \mathrm{mmol} / 1$ sodium will show a greater trend to develop hypernatraemia and periorbital oedema than children receiving a solution with 50 $\mathrm{mmol} / \mathrm{l}$ sodium. I believe they have based this conclusion on unwarranted interpretations of their own data.

(1) Although they intended to give group A more sodium than group B, the actual amounts delivered in the first 12-24 hours were scarcely different: 12 and 11 $\mathrm{mmol} / \mathrm{kg}$ respectively. The effective concentrations of sodium (in mmol/l water consumed) were 58 and 50 .

(2) The authors correctly observe that periorbital oedema is not associated with hypernatraemia. It should not, however, be considered a 'complication' as it merely reflects retention of isotonic saline brought on by physiological responses to volume depletion. Moreover, as the diagnosis of periorbital oedema requires some clinical judgement, the observations should have been made by a person unaware of the children's groupings.

The most important finding of the study is that even moderate to severely dehydrated children can be restored and maintained with an oral glucose-salt solution alone, and that early feeding can be done successfully.

NORBERT HIRSCHHORN 141 Tremont Street, Boston, Massachusetts 02111, USA

Dr Chatterjee and co-workers comment:

We thank Dr Hirschhorn for his very thought provoking comments on our paper, but his assumption that the children in the 2 groups received identical amounts of sodium during initial hydration is not true. The children in group A (treated with the standard solution) received $12 \mathrm{mmol} / \mathrm{kg}$ sodium which is about $14 \%$ higher than the other group which received $10.5 \mathrm{mmol} / \mathrm{kg}$ sodium. This apparently small difference is however significant as the calculated distribution of this excess sodium in the extracellular fluid (which is about $20 \%$ of the body weight) is capable of raising the sodium level by nearly $8 \mathrm{mmol} / \mathrm{l}$. Furthermore, as it was not our intention that the group treated with the standard solution should receive a higher amount of sodium, we took care not to produce sodium overload. It is likely that a less stringent supervision may push the sodium to a critically dangerous level. The other differences which might contribute to hypernatraemia are: (a) In group A additional free water was administered several hours after the start of oral 